\title{
ERA UMA VEZ: OS CONTOS DE FADAS E AS RELAÇÕES DE GÊNERO NA PERSPECTIVA DAS PROFESSORAS
}

\author{
WAS ONCE: THE FAIRY TALES AND GENDER RELATIONS IN THE \\ PERSPECTIVE OF TEACHERS
}

\author{
Maria do Carmo Gonçalo Santos ${ }^{1}$ \\ Amanda Teresinha Gomes Soares ${ }^{2}$
}

\begin{abstract}
RESUMO
Este artigo trata dos contos de fadas e as relações de gênero na perspectiva das professoras em sala de aula. Os contos, como gênero literário, conteúdo e recurso pedagógico, na educação, são perpassados por construções de gênero, que podem influenciar a produção de identidades/identificações dicotômicas de masculino e feminino. Tomamos "gênero" como construção social e categoria de análise, nas perspectivas dialogais e plurais (BENTO, 2006; LOURO, 1997). A abordagem qualitativa (MINAYO, 2002), viabiliza a aproximação da realidade, através dos significados. A Análise de Conteúdo, como técnica de análise de dados (BARDIN, 1977), possibilitou identificar que os contos de fadas são utilizados com finalidade pedagógica pelas professoras. Embora as professoras reconheçam que os contos produzem estereótipos de gênero, revelam que não realizam, sistematicamente, abordagem de gênero, no trabalho com os contos, na prática pedagógica.
\end{abstract}

Palavras-chave: Gênero. Contos de fadas. Representações femininas.

\begin{abstract}
This article deals with fairy tales and gender relations from the teachers' perspective in the classroom. The tales as a literary genre, content and pedagogical resource in education are permeated by gender constructs, which can influence the production of gender dichotomous identities / identifications. We take gender as social construction and category of analysis, in the dialogical and plural perspectives (BENTO, 2006; LOURO, 1997). The qualitative approach (MINAYO, 2002) enables the approximation of reality through meanings. Content Analysis, as a data analysis technique (BARDIN, 1977), made it possible to identify that fairy tales are used for pedagogical purposes by teachers. Although the teachers recognize that the stories produce gender stereotypes, they reveal that they do not systematically carry out a gender approach in working with stories in pedagogical practice.
\end{abstract}

Keywords: Gender. Fairy tale. Representations of women.

1 Doutora em Educação pela UFPE (2016), Mestre em Educação pela UFPE (2004), Especialização em Coordenação Pedagógica pela FAFICA (2003) e Graduada em Pedagogia (2001). Professora da UFPE/CAA. Pesquisadora do Grupo de Pesquisa em Formação de Professores e Profissionalização Docente - UFPE/CNPQ e membro da equipe do projeto de extensão Observatório dos Movimentos Sociais na América Latina (UFPECAA. Tem trabalhos publicados na área de currículo, gênero e formação de professores.

${ }^{2}$ Pedagoga pelo Centro de Educação da UFPE (2018). 


\section{Revista (1) ( \\ Debates Insubmissos}

\section{INTRODUÇÃO}

A literatura infantil é um estilo literário; é conteúdo e recurso pedagógico que possibilita o desenvolvimento da criatividade e representa, através de textos, desejos, expectativas e sentimentos presentes na vida de adultos, adultas, jovens e de crianças. $\mathrm{O}$ trabalho com a literatura infantil, em sala de aula, pode contribuir para o desenvolvimento do pensamento crítico das pessoas, tendo em vista envolver a subjetividade, a sensibilidade e a contextualização. A literatura infantil pode ser considerada como um potente artefato de gênero e de sexualidade, capaz de produzir papeis sociais binários (homens e mulheres).

A partir da literatura infantil situamos os contos de fadas, materializados, sobretudo, em histórias da literatura antiga, cumprindo o papel de colocar as crianças em situações que provocam os seus sentimentos e suas expectativas, fazendo-as pensar em sua realidade. De acordo com Abramovich (2006, p. 120) "[...] os contos de fadas estão envolvidos no maravilhoso, um universo que denota fantasia, partindo sempre duma situação real, concreta, lidando com emoções que qualquer criança já viveu".

Nesse sentido, os contos de fadas apresentam um valor significativo na vida das crianças, pois desenvolvem sua imaginação e, através deles, trazem as narrativas para o contexto social infantil. Percebemos que os contos de fadas são grandes influenciadores na vida e nas relações sociais das crianças, levando-nos a pressupor que as histórias da literatura infantil podem produzir construções de gênero. A pesquisa trata, portanto, das concepções das professoras acerca da relação existente entre o trabalho com os contos de fadas e as construções de gênero.

Gênero, enquanto construção social que (re)produz diferenças, com base em papeis binários para homens e para mulheres é, também, categoria de análise e de intervenção política na investigação e desconstrução desses papeis (LOURO, 1997; SCOTT, 1990).

Buscamos analisar a relação entre contos de fadas e gênero, a partir da perspectiva das professoras. Para tanto, faz-se necessário identificar a importância do trabalho com os contos de fadas em sala de aula; e, ainda, investigar as abordagens utilizadas pelas professoras para o trabalho com esse gênero literário. 
Os contos de fadas são histórias clássicas que atravessam todo o mundo e jamais perdem seus propósitos: encantar e despertar a imaginação das crianças. Por serem tão atrativas, as professoras apresentam essas histórias em sala de aula e observam a sua relevância para os/as alunos/alunas que são instigados/as, pelos contos, de diversas formas, inclusive, nas construções identitárias. Segundo Bettelheim (2002), o referente de bondade que as crianças captam, a partir das personagens dos contos, influencia na identidade delas; assim como outros referentes podem compor as construções de gênero, através dessas histórias.

A partir da sua possível influência na identificação de gênero das crianças, o estudo, sobre os contos de fadas e as relações de gênero, apresenta um valor significativo para nós, comprometidas com a educação crítica, problematizadora das desigualdades.

Em busca de produções nos campos de gênero e educação, que envolvem os contos de fadas, realizamos estudo exploratório, a partir das produções da ANPED - Associação Nacional de Pós-Graduação e Pesquisa em Educação. O recorte se deu nas três últimas reuniões - 35a , 36 e 37 , no GT07 - Educação de Crianças de 0 a 6 anos e no GT23 - Gênero, Sexualidade e Educação. Realizamos a leitura dos resumos dos trabalhos e identificamos os artigos que dialogam com o nosso objeto de pesquisa.

Os trabalhos que mais se aproximaram da nossa pesquisa abordam: "Crianças mirando-se no espelho da cultura: corpo e beleza na infância contemporânea" (SALGADO; FERRARINI; LUIZ, 2012); "Meninos entre meninos num contexto de educação infantil: um olhar sobre as relações sociais de gênero na perspectiva de crianças pequenas" (BUSSSIMÃO, 2012) e "Pedagogias de gênero e sexualidade em artefatos culturais: reflexões sobre uma experimentação" (SEVILLA, 2015).

Estes trabalhos envolvem os estudos culturais e as relações de gênero; por isso, são evidenciados na pesquisa. Entretanto, não localizamos produções que tratem dos contos de fadas no recorte do estudo exploratório. Desse modo, ratificamos a necessidade e importância de investigações que mirem as temáticas de gênero, educação e contos de fadas. 
Através da abordagem qualitativa, realizamos a investigação em uma escola campo de estágio, com duas professoras da Educação Infantil; utilizando a entrevista como procedimento principal de coleta de dados.

O artigo inicia tratando das relações e conceitos de "gênero". Em seguida, aborda a literatura infantil e a (des)construção das identidades de gênero na sala de aula; trata dos contos de fadas, sua origem, influência social e construções de gênero. Situa a metodologia, a análise dos dados e apresenta os resultados da pesquisa.

As análises realizadas apontam que os contos de fadas são presentes nas salas de aula, como conteúdo e recurso pedagógico. As professoras identificam as representações binárias de gênero e, sobretudo, de papeis femininos, nos contos; entretanto, revelam não trabalhar a perspectiva de gênero, em sala de aula, com esses textos.

\section{RELAÇÕES DE GÊNERO E PEDAGOGIAS CULTURAIS: A (DES)CONSTRUÇÃO DE PADRÕES PARA SUJEITOS ${ }^{3}$ HUMANOS NA EDUCAÇÃO}

A categoria "gênero" decorre de um processo histórico de lutas, resistências e conquistas, conhecido como movimento feminista; configurado, geralmente, em ondas, que, de forma geral, buscavam a igualdade de direitos entre as pessoas, nas dimensões civis, sociais, políticas, sexuais e econômicas.

O movimento feminista pode ser situado em vários contextos, de forma plural, embora tenha sido mais evidenciado a partir das óticas europeia e norte americana. Nessa perspectiva, geralmente, é situado em ondas. A primeira onda surge no final do século XIX e início do século XX; e é marcada pela mobilização das mulheres na busca pela conquista da igualdade de direitos civis e sociais. Dentre esses direitos destaca-se o direito ao voto feminino; por isso, convencionou-se chamar de "movimento sufragista".

A segunda onda inicia-se no final da década de 60 , até o final da década de 80 . O feminismo reivindica a liberdade feminina em relação ao corpo, à educação, à produção

\footnotetext{
${ }^{3}$ Não flexionaremos o gênero para sujeitas e sujeitos porque no Nordeste a expressão "sujeita" é uma forma pejorativa de se referir a mulheres com as quais há antipatia.
} 


\section{Revista
Debates Insubmissos}

científica e luta contra as desigualdades culturais e políticas, que influenciavam a vida, tanto profissional como pessoal, das mulheres. Entre as várias reivindicações, destacamos: a luta pela legalização do aborto, a igualdade salarial e o acesso a espaços assumidos apenas por homens. Além das preocupações sociais e políticas, o movimento, nesta fase, volta-se para as construções propriamente teóricas.

A terceira onda, evidenciada na década de 90, envolve e articula-se a novos e diferentes movimentos sociais, que enfatizam as diferenças no interior "da diferença", protestando contra os padrões sociais de identidades fixas de gênero e de sexualidade. $\mathrm{O}$ movimento feminista luta pela igualdade de condições, em vista das transformações da sociedade, sobretudo, pela conquista de políticas públicas que garantam direitos e pelo fim da discriminação de gênero.

Nessa perspectiva configura-se a categoria "gênero", evidenciada no Brasil a partir da década de 80 , que tem como objetivo a luta pela igualdade de direitos, enfatizando que as diferenças entre os gêneros são construções sociais determinadas e/ou fundadas no biológico. Para Louro (1997), o gênero se constitui sobre corpos sexuados, ou seja, não é negada a biologia, mas, enfatizada sua construção social e histórica.

"Gênero" é uma categoria polissêmica, que envolve significados plurais, condicionados por intencionalidades políticas. Para Siqueira (2008), "gênero" é constituído por relações sociais, baseadas nas diferenças percebidas entre os sexos, que, por sua vez, se constituem no interior de relações de poder.

Para nós, "gênero", além das dimensões teórica e de análise, também pode ser compreendido como uma categoria política, nas perspectivas relacional e plural (BENTO, 2006), que visa relações dialogais entre homens e mulheres; bem como, expressa as diversas possibilidades de configurações humanas, contrárias a padrões binários de gênero (masculino e feminino). Esses padrões, geralmente, envolvem e se articulam às dinâmicas das sexualidades, relativas ao desejo, à identidade e às relações humanas.

Nesse sentido, as pessoas vivenciam e constroem seus gêneros e sexualidades em configurações plurais e móveis, tendo em vista que há várias maneiras, expressões e 


\section{Revista
Debates Insubmissos}

possibilidades de se identificar como homem, mulher ou transgênero (aqui tratamos, de forma genérica, as construções para além do binário).

A escola, numa perspectiva crítica de educação, assume função de socialização dos conhecimentos e de formação humana. É também na escola que as crianças vão vivenciar as mais diversas relações; assim, esse é um espaço no qual a criança tem o contato com as diferenças e estabelece trocas culturais, que contribuem para a construção das identidades de gênero.

$\mathrm{Na}$ contracorrente Louro (1997, p. 58), diz que “[...] a escola delimita espaços. Servindo-se de símbolos e códigos, ela afirma o que cada um pode (ou não pode) fazer, ela separa e institui. Informa o "lugar" dos pequenos e dos grandes, dos meninos e das meninas". Nessa perspectiva, a escola influencia na construção da identidade de gênero, quando, por meio de "regras", estabelece posturas e condutas para cada estudante, aonde cada um/uma vai ocupando o seu lugar. De acordo com Louro (1997, p.25):

A escola desempenha um papel importante na construção das identidades de gênero e das identidades sexuais, pois, como parte de uma sociedade que discrimina, ela produz e reproduz desigualdades de gênero, raça, etnia, bem como se constitui em um espaço generificado.

Portanto, nessa discussão, Louro (1997), nos mostra que as escolas podem ser locais onde a diferença seja valorizada e a desigualdade questionada, através da partilha, discussão e análise de modos de vida plurais e de culturas diversas. Dessa forma, uma instituição que realize um trabalho visando à igualdade de gênero, e à desconstrução do binarismo, será um espaço para todos/as; pois, assim, os/as estudantes compreenderão que homens, mulheres, transgêneros, cisgêneros apresentam-se para a sociedade da maneira como desejam e se identificam.

O olhar atento para "as pedagogias culturais" revela que o currículo escolar é permeado por tensões e intenções que podem incluir ou excluir socialmente. De acordo com Sabat (2001, p. 9), “[...] tais pedagogia e currículo culturais, entre outras coisas, produzem valores e saberes; regulam condutas e modos de ser; fabricam identidades e representações; constituem certas relações de poder”. Através dos discursos, das Representações Sociais, das 


\section{Revista \\ Debates Insubmissos}

experiências e recursos, a pedagogia cultural forma e informa os sujeitos da relação pedagógica.

As pedagogias culturais têm o poder de produzir, disseminar e reproduzir referentes para as construções de gênero e de sexualidade, com o suporte dos artefatos culturais, como o livro didático, os quadros de avisos, as músicas, livros de histórias, e os contos infantis. Giroux e Mclaren (1995, p. 144), dizem que:

Existe pedagogia em qualquer lugar em que o conhecimento é produzido, em qualquer lugar em que existe a possibilidade de traduzir a experiência e construir verdades, mesmo que essas verdades pareçam irremediavelmente redundantes, superficiais próximas ao lugar - comum.

Assim, a pedagogia está presente nas relações que promovem a construção de conhecimentos, em espaços escolares e não escolares. Entretanto, ao mesmo tempo em que tem poder para produzir identidades de gênero, de classe, de raça, também pode ressignificar tais "verdades".

As relações existentes entre educação e cultura estão diretamente envolvidas nos processos de construção de identidades e subjetividades, inclusive, na produção de gêneros. As pedagogias e artefatos culturais, como potentes produtores identitários, dizem do "ser homem" e do "ser mulher". Vidal (2008, p. 2) afirma que: "A música, os brinquedos e jogos eletrônicos, o cinema e o teatro, os meios de comunicação, a literatura infantil. Elas ensinam, entre muito outras coisas, diferentes e conflitantes formas de conceber e de viver o gênero e a sexualidade".

Por meio desses diversos fenômenos culturais, o/a educador/a pode se beneficiar utilizando-os como espaços e estratégias pedagógicas na produção de conhecimento, inclusive, aproximando educação e mídia. Segundo Giroux e Mclaren (1995, p.148):

As imagens e sons produzidos, por exemplo, pelo rádio, pela televisão, pela imprensa, pelo filme e pelos computadores podem ser questionados e contestados através das experiências que os/as estudantes utilizam para dar significados ao mundo, através da linguagem que eles/elas usam para entender essas experiências e, dessa forma, a própria produção do conhecimento. 
Através das pedagogias culturais o/a educador/a tem possibilidades para trabalhar, apresentar e desenvolver os mais diversos assuntos, como: o racismo, a família, a violência, o trabalho, o gênero, a sexualidade. Em relação a gênero e sexualidade, no que se refere aos artefatos culturais, destacamos a literatura infantil, pelo alcance subjetivo e objetivo na produção dos papeis sociais de gênero e suas possibilidades de desconstrução.

A produção de identidades/identificações, através dos modelos de gênero, veiculados também pelos artefatos culturais, possibilita que as crianças se (re)conheçam nos discursos imagéticos e textuais da literatura infantil.

\subsection{A literatura infantil e as identidades de gênero}

Neste trabalho situamos a literatura infantil como um potente artefato de gênero e de sexualidade, tendo em vista sua influência na construção das identidades binárias (de meninos e de meninas) desde muito cedo. Para Bento (2014a, p. 254), “[...] as identidades são pontos de apego temporário às posições-de-sujeito que as práticas discursivas constroem para nós"; e

essas práticas dizem da cultura produzida socialmente. No nosso caso, a cultura, considerada "a referência", "a norma", evidencia a heterossexualidade e a cisgeneridade.

A criança, em contato com a literatura, pode desenvolver a criatividade, a imaginação, transformando sua visão de mundo e, consequentemente, tornando-se um sujeito mais crítico. De acordo com Bettelheim (2002, p. 12), a literatura infantil objetiva "[...] desenvolver a mente e a personalidade da criança"; e não só divertir e informar, mas, construir e partilhar experiências.

Nesse sentido, a literatura possibilita, à criança, o desenvolvimento emocional e social. Para tanto, o hábito da leitura é um processo que ultrapassa o ambiente escolar; mas, enquanto finalidade pedagógica, intencional, desenvolve-se nesse espaço. Além disso, o trabalho em sala de aula, com a literatura infantil, pode contribuir para desenvolver o pensamento crítico, através da relação entre o texto lido (escrito e/ou imagem) e o cotidiano das crianças.

A utilização da literatura infantil, na sala de aula, pode ajudar as crianças a refletirem sobre os papeis arbitrários de gênero, construídos para meninos e para meninas, visando à 


\section{Revista \\ Debates Insubmissos}

construção dialogal e plural das relações de gênero (BENTO, 2006), que se inscrevem em práticas mais democráticas.

Para Daros (2013), a literatura infantil pode ser instrumento problematizador das relações de gênero e de sexualidade, no diálogo entre realidade e fantasia, a partir do trabalho crítico das e dos docentes. A realização do trabalho com a literatura e as identidades de gênero, pode oferecer às crianças a releitura dos/as personagens e das suas ações, problematizando os papeis de gênero, a realidade e a desigualdade nas relações.

Dentre os vários gêneros literários, damos destaque aos contos de fadas, por estarem mais diretamente ligados a personagens que expressam construções de gênero idealizadas. Esses possibilitam a problematização dos significados atribuídos aos sujeitos humanos pela sociedade, junto às crianças.

\subsection{Os contos de fadas: origem e finalidades educativas}

Os contos de fadas têm o poder de "transportar" o/a leitor/a para um mundo de fantasias e sonhos e, ao mesmo tempo, situá-lo/a em seu cotidiano, incutindo valores morais, relações e sensações afetivas, conflituosas, de disputas; além de referentes de bondade e de maldade. A narrativa envolve, sobretudo as crianças, nos papeis de heróis/heroínas, fadas, príncipes e princesas, mexendo com sentimentos e expectativas que ultrapassam a imaginação e evocam as expectativas pessoais (BASTOS; NOGUEIRA, 2016).

Em sua origem, os contos de fadas eram contados por moradores/as do campo, que se juntavam e passavam a noite em volta de fogueiras, contando e ouvindo histórias com os diferentes temas. Essas narrativas não eram destinadas diretamente às crianças; mas, como uma maneira de distrair as noites dos/as adultos/as. De acordo com Corso e Corso (2006, p.14):

A função das narrativas maravilhosas da tradução oral poderia ser apenas a de ajudar os habitantes de aldeias camponesas a atravessar as longas noites de inverno. Sua matéria? Os perigos do mundo, a crueldade, a morte, a fome, a violência dos homens e da natureza. Os contos populares pré-modernos talvez fizessem pouco mais do que nomear os medos presentes no coração de todos, adultos e crianças, que se reuniam em volta do fogo enquanto os lobos uivavam lá fora, o frio recrudescia e a fome era um espectro capaz de ceifar a vida dos mais frágeis, mês a mês. 


\section{Revista \\ Debates Insubmissos}

Nessa perspectiva mítica, entendemos que muito antes da escrita, os diferentes povos, não só europeus, por meio da tradição oral, já transmitiam o seu aprendizado de geração a geração. Além disso, utilizavam essa tradição como forma de explicar a realidade, as vivências e construir códigos morais.

Oliveira (2010, p.13), diz que "[...]os contos de fadas nada mais eram do que relatos de fatos da vida de pessoas simples, recheados de conflitos, aventuras e muitas vezes não eram indicados a serem contados para as crianças". Enquanto relato de vida, não havia tratamento pedagógico da linguagem, dos fatos; por isso, não era indicado para crianças, embora, esse cuidado não fosse vivenciado por muitas culturas; assim como, na contemporaneidade, muitas crianças não são poupadas de histórias que envolvem violência, tragédias ou apelo sexual.

A falta de registro escrito dessas histórias, ao longo do tempo, dificultou o resgate de algumas memórias, culturas e histórias. Os primeiros contos de fadas tiveram seus registros iniciais realizados pelo francês Charles Perrault. Ele não criou suas próprias narrativas; mas, recolheu as histórias contadas oralmente pelo povo das diversas vilas, após viagem e investigação, em busca de registros. Assim, Perrault não foi o autor das histórias, porém as adaptou e, possivelmente, silenciou alguns temas, como por exemplo: a violência e a sexualidade, tornando seus textos "adequados" e aceitos pela população.

Segundo Falconi e Farago (2015, p. 91):

Ao coletar histórias populares, Perrault publicou as versões imortais como A Bela Adormecida, A Gata Borralheira, Barba Azul, As Fadas, Pele de Asno, dentre outras. Verificamos que sua intenção não era apenas de divertir a população, mas também continha a ideia de moralizar e instruir ensinamento ao indivíduo, a princípio adulto e posteriormente a crianças.

Perrault tornou-se o primeiro e mais conhecido escritor dos contos de fadas, destacando-se por sua preocupação e empenho em resgatar essas histórias, transformá-las e reescrevê-las, numa literatura dedicada às crianças. Sua primeira publicação foi "Contos da Mãe Gansa", onde reuniu vários contos de fadas.

Posteriormente, surgiram Jacob Grimm e Wilhelm Grimm, mais conhecidos como os irmãos Grimm que eram linguistas e pesquisadores de culturas. Eles realizaram pesquisas da 


\section{nevistet \\ Debates Insubmissos}

tradição popular alemã, apresentando várias histórias em seus livros. Oliveira (2010, p. 21), nos diz que "[...] eles percorreram a Alemanha registrando as narrativas populares que recolhiam de pessoas humildes, muitas vezes analfabetas: comadres de aldeia, velhos camponeses, pastores, barqueiros, músicos e cantores ambulantes”. Dessa maneira, os irmãos Grimm investigaram a cultura do povo alemão, com foco nos elementos linguísticos alemães. Coelho (2003, p. 23), afirma que:

Em meio à imensa massa de textos que lhes servia para os estudos linguísticos, os Grimm foram descobrindo o fantástico acervo de narrativas maravilhosas, que, selecionadas entre as centenas registradas pela memória do povo, acabaram por formar a coletânea que é hoje conhecida como Literatura Clássica Infantil.

Através da inquietação dos estudos linguísticos, os irmãos Grimm descobriram as histórias contadas pelo povo e ficaram fascinados. A partir desses estudos, trouxeram narrativas para a literatura, tendo como público principal, as crianças. Desse modo, não alteravam o enredo e nem as/os personagens, mas não os tratavam fielmente, ou seja, realizavam edições e traziam, em suas histórias, o "mundo maravilhoso de fantasias".

As diferenças encontradas entre as produções dos irmãos Grimm e as de Charles Perrault é que esse direcionava a leitura para a Corte, já os Grimm produziram uma obra mais social, buscando a preservação do patrimônio literário do povo alemão e destinada à população em geral, adultos ou crianças. Em relação à produção dos Grimm, Oliveira (2010, p. 21) afirma que:

Seu trabalho ganhou proporções que romperam a esfera nacional de importante documento das tradições populares alemãs para espalhar-se pelo mundo, sendo traduzido e imortalizado entre crianças, jovens e adultos que contam e recontam as histórias por eles escolhidas.

Após as histórias de Perrault e dos irmãos Grimm, surge no século XIX o dinamarquês Hans Chrístian Andersen, que escreveu suas próprias histórias, inserindo elementos maravilhosos, a magia e o romantismo. Coelho (2003, p. 25), diz que "Andersen passou à história como a primeira vez autenticamente romântica a contar histórias para as crianças e a sugerir-lhes padrões de comportamento a serem adotados pela nova sociedade que naquele momento se organizava". 


\section{nevistet \\ Debates Insubmissos}

Andersen difere dos dois autores anteriormente citados, pois seu foco não era recolher as histórias da tradição popular; ele criava histórias novas, mas sem deixar de seguir um roteiro tradicional. Alguns contos famosos de Hans Chrístian Andersen são: O Patinho Feio, O Soldadinho de Chumbo, A Roupa Nova do Imperador. Identificamos um elemento de aproximação entre as narrativas de Andersen e as dos irmãos Grimm, em relação ao silenciamento das situações de violência, nas histórias, que apontavam para o cuidado com a faixa etária do público leitor.

No Brasil, os contos de fadas surgiram em meados do século XIX. Uma das primeiras histórias foram os contos de Carochinha. As histórias publicadas no Brasil eram algumas das traduções e adaptações das narrativas de Perrault e dos irmãos Grimm, com características como: príncipes e princesas, reis e rainhas, bruxas, anões, gigantes; entre outros seres fantásticos.

Os contos de fadas surgiram, há muito tempo, com propósitos bem diferentes dos contos atuais. Além disso, é importante registrar que os contos das tradições e culturas indígena e africana não tiveram o mesmo tratamento e atenção. Ainda hoje esses contos são mencionados como folclore e, muitos deles, não foram registrados e publicados, cabendo pesquisas e investigação.

No que se refere à literatura dos contos e aos escritores aqui referidos, situamos a contribuição significativa desses autores para que os contos de fadas fossem ressignificados, transformados, contados e recontados. Importante salientar que os escritores são homens e que as implicações de gênero, nesses contos, envolvem o contexto cultural e, sobretudo, o ponto de vista de gênero, de quem "conta o conto".

A disseminação desses contos possibilita que adultos e crianças se aproximem da prática da leitura, das vivências cotidianas e das relações históricas. De acordo com Oliveira (2010, p. 20):

[...] é possível perceber que os contos de fadas são histórias muito atuais, porque todas elas são alimentadas de sabedoria prática que não envelhece, pois se fundamenta na natureza humana, nos sentimentos, medos, angústias, esperanças, alegrias e esses aspectos continuam os mesmos, independente do século. 
Os contos de fadas, como narrativas clássicas, também revelam os valores, os anseios e tradições preservadas ao longo do tempo. Essas histórias têm o poder de direcionar a um mundo mágico, apresentando uma realidade, de "maneira encantadora" e permeada de significados sociais. Através dos contos vemos, sobretudo, a preservação de referentes de gênero que orientam práticas sociais, perpetuando desigualdades ao longo do tempo; embora contos de resistência estejam surgindo.

\subsection{Os contos de fadas e as relações de gênero}

Nos contos de fadas as crianças se deparam com situações cotidianas, que envolvem sentimentos e expectativas em relação à vida. Bettelheim (2002), apresenta algumas dessas emoções: a agressividade, o medo, o descontentamento com familiares. Na história de João e Maria é trabalhado o medo da rejeição; em Cinderela, a rivalidade e inveja entre irmãs e a relação com a madrasta; a separação, em Rapunzel. As crianças passam a se identificar com essas histórias, localizando alguns de seus medos e possibilidades de enfrentamento. Assim, uma das várias características dos contos de fadas, é o poder que eles têm de fazer conhecer e compreender desafios e possibilidades. Na contracorrente, esses referentes também podem inquietar aqueles e aquelas que percebem os atravessamentos ideológicos e não se identificam com os enredos, discursos e/ou personagens.

Esse gênero literário e artefato cultural possibilita identificações e construções de gênero e de sexualidade, tendo em vista seu poder de transportar o sujeito para as dimensões objetivas e subjetivas, de transitar entre a fantasia e a realidade. Para Bastos e Nogueira (2016), os contos podem ser contados e recontados de acordo com as interpretações e visões dos/as autores/as. Nesse sentido, podemos inferir que carregam as marcas culturais do contexto; bem como, das compreensões de gênero dos autores (majoritariamente homens) e das autoras.

Através das imagens, cores, Representações Sociais, discursos, os/as leitores/as apreendem, incorporam e podem reproduzir e/ou ressignificar tais referentes. Falconi e Farago (2015, p. 96) dizem: 


\section{novist \\ Debates Insubmissos}

A criança passa a interagir com as histórias, passando a acrescentar detalhes, personagens ou também lembrar fatos que passaram despercebidos pelo narrador. Essas histórias são fundamentais para que as crianças estabeleçam a sua identidade, compreendam melhor as relações familiares [...].

Os teóricos nos mostram que os contos são apresentados de maneira simples; as/os personagens (príncipes e princesas, fadas, bruxas), passam por problemas presentes no cotidiano e, muitas vezes, a criança se identifica com a história. Geralmente, ela acaba se colocando no lugar do/a personagem. Em relação a gênero e sexualidade, os contos, de uma forma geral, produzem um ideal de mulher, ligado a papeis sociais de gênero, que expressam a lógica da "bela, recatada e do lar". Na contramão, as mulheres que evidenciam a sexualidade, lidam com o poder, com o conhecimento e com o espaço público, assumem a imagem estereotipada da "bruxa", assustadora, ardilosa, camaleônica, com uma verruga no nariz e corcunda. Os príncipes, geralmente, assumem a figura do salvador, guerreiro e provedor.

Podemos analisar, na citação abaixo, o referencial de herói, que é mencionado no masculino genérico, limitando esse papel à figura masculina. Segundo Falconi e Farago (2015, p. 108):

A criança é levada a se identificar com o herói bom ou belo, mas não por ser devido à bondade ou à beleza e sim por ela sentir nele a superação dos seus problemas, surgindo em seu inconsciente o desejo de bondade e beleza e também a necessidade de segurança e proteção. Assim pode superar seus medos que a proíbe de enfrentar os perigos e ameaças que sente a sua volta.

A relação entre os contos de fadas e gênero pode conduzir à formação de vários estereótipos na vida das crianças, meninas/os ou transgêneros; por elas/eles se identificarem com os/as personagens e buscarem trazer, para a sua realidade, as características desses personagens. Giroux (1995, p.55), ao tratar dos desenhos da Disney, diz que eles “[...] fornecem modelos e protótipos para as famílias, escolas e comunidades". Esses "modelos" produzem discursos sobre "o que é ser menina, menino", "o que é a infância”, a "fantasia". Os protótipos de gênero, presentes nesses artefatos, não são neutros, coincidência ou naturais; eles agem essencializando ou naturalizando papeis.

Ao analisar o conto de fadas "Cinderela", as autoras Bastos e Nogueira (2016) revelam que "[...] os contos de fadas servem para acentuar e perpetuar estes paradigmas 
femininos, além de (re)afirmarem que o modelo ideal de mulher é aquele submisso, que merece e recebe a tutela do poder divino e/ou mágico e masculino, como é o caso de Cinderela". Essas construções de gênero e de sexualidade expressam e ratificam os padrões patriarcais, heterossexuais, de masculinidade hegemônica e eurocêntrica, que atuam de maneira performática (BUTLER, 2013). Através de discursos reiterados e difusos, as pessoas são levadas a naturalizar tais modelos.

Entretanto, como os discursos são plurais e difusos, os contos de fadas também podem ser relidos, reinterpretados e ressignificados. Este trabalho, que trata dos contos de fadas e das relações de gênero, na perspectiva das professoras, instiga a pensar nas suas construções de gênero, no exercício de (re)leitura, (re)interpretação e nos significados atribuídos aos contos, na prática docente. Para tanto, buscamos saber das professoras o que pensam da relação entre contos de fadas e gênero.

\section{O PERCURSO DA PESQUISA E A POSSIBILIDADE DE (RE)CONTAR SIGNIFICADO}

Por meio da sistematização do conhecimento científico, o caminho desenvolvido na pesquisa está relacionado com o método utilizado, as/os participantes, o local, as/os autores, os instrumentos e os procedimentos que acompanham o tipo da pesquisa. "A metodologia inclui, simultaneamente, a teoria da abordagem (o método), os instrumentos de operacionalização do conhecimento (as técnicas) e a criatividade do pesquisador (sua experiência, a sua capacidade pessoal e sua sensibilidade)" (MINAYO, 2002, p.16).

A metodologia vai além das técnicas e dos procedimentos; ela diz respeito ao caminho escolhido para alcançar os objetivos propostos pela pesquisa e os resultados obtidos para a análise de dados. A abordagem qualitativa articula-se ao trabalho de investigação nas ciências sociais e humanas. Assim, possibilita analisar a relação entre os contos de fadas e gênero, a partir da perspectiva das professoras. Minayo (2002, p. 21), diz que: “[...] a pesquisa qualitativa não se limita a quantidades, e sim, na compreensão do objeto de estudo. Ou seja, ela trabalha com o universo dos significados, dos motivos, das aspirações, das crenças, dos 


\section{novist

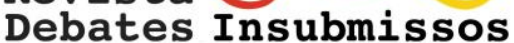

valores e das atitudes". A abordagem qualitativa dá suporte ao nosso estudo, que trata da relação dos contos de fadas e gênero, porque vai em busca dos significados atribuídos pelas professoras a essa relação.

O campo de pesquisa foi a Escola ${ }^{4}$ Auradon, localizada no município de Bom Conselho, no agreste meridional do estado de Pernambuco, a $276 \mathrm{~km}$ da capital, Recife. A escola possui 350 estudantes. A escolha dessa escola aconteceu, principalmente, pelo contato direto com a gestão, por meio do estágio, chamando nossa atenção pela proposta progressista de educação. Duas professoras formadas em Pedagogia, que sinalizaram trabalhar com contos de fadas em suas aulas, contribuíram para o levantamento e análise dos dados.

O instrumento de pesquisa, para coleta de dados, foi a entrevista. De acordo com Gomes (2002, p. 57):

A entrevista é o procedimento mais usual no trabalho de campo. Através dela, o pesquisador busca obter informes contidos na fala dos autores sociais. Ela não significa uma conversa despretensiosa e neutra, uma vez que se insere como meio de coleta dos fatos relatados pelos atores, enquanto sujeitos da pesquisa que vivenciam uma determinada realidade que está sendo focalizada.

A entrevista atende às demandas do nosso objeto de pesquisa, no intuito de coletar dados relativos à perspectiva das professoras, sobre os contos de fadas e gênero, aproximando-nos da realidade. Dentre os tipos de entrevistas, optamos pela "entrevista semiestruturada", tendo em vista sua flexibilidade e dinamicidade no exercício do diálogo. De acordo com Manzini (2004, p.3):

É possível um planejamento da coleta de informações por meio da elaboração de um roteiro com perguntas que atinjam os objetivos pretendidos. O roteiro serviria, além de coletar as informações básicas, como um meio para o pesquisador se organizar para o processo de interação com o informante.

Assim, estruturamos um roteiro temático aberto para orientar o diálogo, com base nos objetivos da pesquisa. Para a análise de dados, trabalhamos com a Análise de Conteúdo (BARDIN, 1977), como uma técnica de análise do material da pesquisa, através do processo de organização, tratamento e inferência dos dados. A categorização, realizada a partir da

\footnotetext{
${ }^{4}$ Auradon - considerada a pátria de todos os príncipes e princesas, vilões e vilãs da Disney é apresentada no filme Descendente produzido pelo Disney Channel.
} 
leitura das entrevistas transcritas, favoreceu a identificação de categorias empíricas da pesquisa. Segundo Gomes (2002, p.88), “A categorização tanto pode ser realizada previamente, exigindo um conhecimento sólido por parte do pesquisador para encontrar um esquema classificatório adequado ao assunto a ser analisado, como pode surgir a partir da análise do material de pesquisa".

No caso da pesquisa, a categorização foi feita a partir da análise do material, fundamentada no estudo bibliográfico, o que possibilitou a identificação das seguintes categorias e respectivos sentidos: contos de fadas (fantástico, finalidade pedagógica), gênero (dicotomia, optativo), contos de fada e gênero (representação feminina, identificação).

\section{CONTOS DE FADAS E GÊNERO: RELAÇÕES PRESENTES NO COTIDIANO ESCOLAR, A PARTIR DAS PROFESSORAS}

A discussão acerca da relação entre os contos de fadas e gênero, a partir da perspectiva das professoras, diz do compromisso de uma educação voltada para a justiça social. No cotidiano escolar, a prática pedagógica das professoras e professores da Educação Básica, geralmente, as interpela a lidar com questões de gênero, mesmo que não percebam ou não realizem a intervenção. Nesse artigo é situada a relação entre contos de fadas e gênero, a partir das professoras.

$\mathrm{Na}$ categoria contos de fadas as professoras atribuíram o sentido de fantástico, como também de finalidade pedagógica. Quanto à categoria gênero, ela foi evidenciada como dicotômico e optativo. Na última categoria, referente à relação entre contos de fadas e gênero, foi abordado o sentido da representação feminina presente nos contos de fadas, como da identificação de gênero com os e as personagens.

Para falar sobre os contos de fadas e as relações de gênero, iniciamos expondo o que as professoras entendem sobre os contos de fadas, ou seja, o que os contos significam para cada uma delas. Assim, as duas professoras apresentam os contos de fadas ligados ao mundo 


\section{nevistet

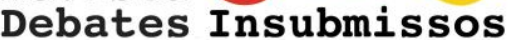

fantástico. Bela ${ }^{5}$ diz que o conto de fadas "[...] é uma história onde tem personagens fantásticos". Moana ${ }^{6}$ responde que "[...] o conto de fadas é um tipo de história que nos transporta a um mundo fantástico, muitas vezes mágico e cheio de fantasia, com personagens folclóricos, animais falantes, príncipes, fadas e gnomos".

Destacamos da fala das professoras a categoria fantástico, um significado presente em diversos livros a respeito do conceito de contos de fadas. Como apontam Corso e Corso (2006, p. 26) “O que entendemos aqui por conto de fadas é a função da onipresença de algum elemento mágico ou fantástico nessas histórias. Contos de fadas não precisam ter fadas, mas devem conter algum elemento extraordinário, surpreendente, encantador”. Desse modo, os contos de fadas, para as professoras, dizem de algo irreal, abstrato, que está no nível do irracional.

Nessa esteira, os textos chamam a atenção do público infantil, sobretudo, por serem simples e pertencentes a um mundo imaginário. As professoras parecem perceber a importância da utilização dos contos, no trabalho com as crianças, ratificando esse significado. Ainda para afirmar essa fantasia, Corso e Corso (2006, p.26), dizem que:

O elemento fantástico presente enquanto maravilhoso nessas narrativas cumpre a função de garantir que se trata de outra dimensão, de outro mundo, com possibilidades e lógicas diferentes. Assim fazendo, os argumentos da razão e da coerência já são barrados na porta, e a festa pode começar sem suas incômodas presenças, bastando pronunciar as palavras mágicas Era uma vez... como uma senha de entrada.

\footnotetext{
${ }^{5}$ Bela e Moana são os pseudônimos utilizados para nomear as professoras da pesquisa, que se referem a personagens de histórias infantis. As personagens foram escolhidas pelas professoras entrevistadas, a partir das suas identificações com as princesas. A professora Bela diz escolher essa personagem, como pseudônimo, pela identificação com a personagem, que faz tudo para defender a família e não se importa com aparência física. A princesa Bela, no conto, é considerada a moça mais bela da cidade, porém, é muito criticada e considerada estranha, por seu amor à leitura. É uma princesa aventureira, empoderada, que luta pela libertação do seu pai. Na história, Bela se apaixona pela Fera, mostrando que seu o sentimento é maior do que a imagem assustadora da Fera. Bela luta contra o controle da Fera. Para uma análise crítica da personagem Bela, ver Giroux (1995). ${ }^{6} \mathrm{~A}$ escolha da professora Moana, por esse pseudônimo, se deu pela identificação com a coragem da personagem, que é capaz de tudo, por quem ama. A professora afirma que os clássicos ainda são as histórias preferidas dela; porém, se encantou com o conteúdo do filme de Moana que, sem príncipe, conquista um final feliz igual às outras. Moana é uma princesa do filme, produto da Disney, uma moça independente, apaixonada e valente que enfrenta uma aventura para salvar o seu povo.
} 


\section{noviste \\ Debates Insubmissos}

Nesse sentido, identificamos o quanto os contos de fadas têm a capacidade de direcionar, tanto quem os lê como quem os ouve, para um mundo fantástico, onde a imaginação toma conta do momento e distancia da realidade, da racionalidade. E essa capacidade é apresentada pelas professoras. Por serem histórias de fácil compreensão e com um significado cultural amplo, os contos de fadas são lidos e trabalhados dentro da sala de aula como um instrumento que ajuda no desenvolvimento da imaginação e na criatividade dos/das alunos/as. A capacidade de ultrapassar os limites do racional, através dos contos de fadas, pode remeter à liberação de desejos, sonhos, fantasias; bem como, ao alheamento, ao afastamento da criticidade, tendo em vista que o roteiro e desfecho da história estão prontos, preestabelecidos.

Os contos de fada também assumiram o sentido de finalidade pedagógica. Em sua fala, Moana deixa explícita a utilização dos contos de fadas:

Utilizo com frequência em minhas aulas, com finalidades diversas, que vão de uma leitura deleite (no início da aula, ou após o recreio), para interpretação de texto, apropriação do sistema de escrita (utilizando palavras-chave), desenvolvimento da oralidade (com leitura de imagens e/ou reconto do conto), produção escrita (individual ou coletiva). Até mesmo em um relaxamento (na aula de movimento), com sons da natureza, todos deitados, olhos fechados, imaginando o conto narrado.

A abordagem didática, para trabalhar com os contos, segue finalidades cognitiva e psicomotora; entretanto, a dimensão política não foi situada nessa fala. Ao articularmos essa intencionalidade pedagógica com a dimensão do fantástico, também atribuída à finalidade dos contos, percebemos que a reflexão crítica do trabalho docente, acerca dos discursos veiculados pelos contos, não é realizada.

Bela afirma que utiliza os contos de fadas "[...] geralmente em um momento de leitura deleite, onde procuro colocá-los dentro da história, sempre de forma lúdica”. A ludicidade ganha vulto nessa explicação e, também, não trata da dimensão política na abordagem com o conto.

Diante das falas das professoras, percebemos que os contos de fadas têm tempos, espaços e abordagens didáticas diversas na sala de aula, com intencionalidades pedagógicas 
definidas e plurais. A presença das construções de gênero nos contos é visível, mas não há um trato aprofundado e crítico por parte das professoras.

A literatura infantil e, especificamente, os contos têm o potencial de interferir na formação ética, nas relações e expectativas das crianças, tendo em vista articular as dimensões objetiva e subjetiva, que envolvem a prática da leitura e das narrativas. Segundo Oliveira (2010, p.44) "A contação de histórias tem o papel de incentivar a leitura e a função da literatura como arte, objetivando-se transmitir valores que determinam atitudes éticas, que possibilitam a melhor convivência no ambiente escolar".

A contação de histórias é técnica de ensino utilizada pelas professoras da pesquisa que, inclusive, favorece o reconto, importante para a releitura de imagens e textos. São várias as histórias com enredos e personagens diferentes que chamam a atenção das crianças.

Quando indagadas sobre quais os contos mais utilizados e quem os escolhe Bela diz que tanto ela como os/as alunos/as escolhem, e os mais pedidos são "[...] as histórias das princesas e dos príncipes”. Já Moana, em sua fala, mostra que “[...] os contos mais utilizados são os clássicos (A Bela e a Fera, Cinderela, Branca de Neve...).” Nesse sentido, todos esses contos envolvem imagens de princesas e príncipes, numa relação binária, com padrões de gênero bem demarcados, que, se não forem revisitados, podem ser introjetados como modelos "para meninos" e modelos "para meninas".

O que destacamos das falas das professoras é que, mesmo com o passar do tempo, os contos clássicos ainda são escolhidos e até mesmo os preferidos das crianças, pois são narrativas que conservam os seus significados. Oliveira (2010, p. 20), afirma: “[...] que os contos de fadas são histórias muito atuais, porque todas elas são alimentadas de sabedoria prática que não envelhece."

Diante da fala das professoras é possível perceber que os contos de fadas estão ligados àquilo que é fantástico, ao mundo mágico; porém, mesmo com essa magia, são histórias que apresentam valores e padrões sociais. A partir desses referentes, as professoras utilizam os contos de fadas com finalidades pedagógicas de estimular a imaginação, desenvolver a ludicidade e construir conhecimentos. 


\section{Revista \\ Debates Insubmissos}

O trabalho com os contos de fadas é vivenciado, nas salas de aulas, como forma de influenciar na leitura, imaginação e criatividade das crianças, inclusive, ajudando a enfrentar seus medos interiores. Segundo Bettelheim (2002, p.6):

Esta é exatamente a mensagem que os contos de fada transmitem à criança de forma
múltipla: que uma luta contra dificuldades graves na vida é inevitável, é parte
intrínseca da existência humana - mas que se a pessoa não se intimida, mas,
se defronta de modo firme com as opressões inesperadas e, muitas vezes,
injustas, ela dominará todos os obstáculos e, ao fim, emergirá vitoriosa.

Assim, os contos de fadas são grandes influenciadores na vida das crianças e trazem uma carga diversa de significados para elas. As professoras dizem perceber essa influência quando realizam as leituras das narrativas e identificam a produção de seus efeitos nas crianças, mas não evidenciam as questões de gênero no seu trabalho.

Os "novos contos de fadas", termo utilizado por Vidal (2008), apresentam histórias baseadas nos clássicos; porém, com uma perspectiva contemporânea, que envolve personagens de mulheres mais ativas, relacionadas a temas atuais. Sobre os "novos contos" Moana diz que: “[...] atualmente, os novos contos de fadas também são solicitados pelos/as estudantes, os atuais estão mudando a imagem da mulher (Frozen, Moana, Malévola, Valente...). Todos presentes no cotidiano das crianças."

A possibilidade de as crianças escolherem o conto e terem disponíveis os "novos contos" indica uma relação democrática entre professora e alunos/as, bem como, a abertura para outros referenciais que abordem construções de gêneros plurais. A professora percebe as contribuições dessa literatura em relação a gênero, embora não mencione explorar essa dimensão.

Através dos "novos contos" as crianças podem passar a se identificar com personagens, mais empoderadas, destemidas e atuantes; embora os resquícios dos estereótipos e papeis de gênero ainda sejam conservados em alguns contos. De todo modo, “[...] os novos contos de fadas ensinam, entre outras coisas, como ser homem e mulher." (VIDAL, 2008, p. 2), de formas mais democráticas. Na perspectiva das diferenças de gênero, esses contos têm ajudado a 'borrar' as fronteiras dos papeis de gênero, apesar de as professoras não intervirem diretamente nessa discussão dos papeis. 
A percepção das mudanças é anunciada na fala de Moana, quando diz da representação feminina nos contos que a Disney apresenta, com novas narrativas e revisão de padrões de gênero. Segundo Vidal (2008, p. 7), "Em tais contos, não se trata de somente inverter padrões: os fracos passam a ser fortes e vice-versa. Mas operam algumas transgressões importantes como a da princesa que prefere ficar sozinha, ou que prefere até pintar as unhas a ouvir a falação dos pretendentes".

Esses novos contos apresentam uma conotação, um sentido diferente das narrativas clássicas. São princesas que agora não estão à espera de um príncipe encantado para salvá-las, mas que conquistam o que desejam sozinhas, e embarcam numa aventura em que enfrentam seus medos e perigos. Assim, são histórias em que os príncipes e as princesas apresentam masculinidades e feminilidades de modos diferentes das princesas e príncipes romantizados, embora preservem os binarismos de gênero.

A professora Moana chama a atenção para o interesse das crianças em relação aos novos contos, embora mantenham o desejo por contos clássicos. Ela diz: "É notório o interesse pelas novas histórias, todavia, os clássicos ainda despertam o interesse, principalmente, se forem contados de uma maneira interessante. Além do fato de ser possível encontrar todos os contos (clássicos e atuais) em DVD”. A professora Bela, em sua fala, também mostra que os contos, que chama de clássicos, são preservados em termos materiais e afetivos. Ela diz: “[...] com o passar dos tempos observa-se que os clássicos não estão sendo esquecidos, porém, novas histórias estão surgindo".

As professoras não falam de uma "troca", mas, da chegada de novos contos; bem como, da presença dos contos clássicos e contemporâneos em um mesmo espaço. Moana enfatiza a importância de como são contados e a viabilidade de ter acesso aos recursos digitais para o trabalho com os contos. Através dos relatos das professoras podemos identificar suas percepções acerca das mudanças de construções de gênero nos contos, porém, apenas evidenciam a presença desses contos nas aulas e o interesse das crianças; mas, não revelam intervenção pedagógica em relação aos contos e gênero.

A fala de Moana nos remete para a importância do trabalho pedagógico na apresentação desses contos, tendo em vista as possíveis "ênfases e/ou omissões no currículo" 


\section{nevistet \\ Debates Insubmissos}

(CANEN; MOREIRA, 2001); pois, podemos, enquanto profissionais, dar mais destaque a uma personagem, história ou situação, dependendo dos nossos interesses políticos. Assim, não é apenas a escolha deste ou daquele conto que vai influenciar na construção de gênero; mas, o uso que se faz dele, através das entonações, pausas, diminutivos e aumentativos, adjetivos, cores, representações.

Em relação a gênero as professoras também anunciam suas compreensões. A análise dos dados mostra que "gênero" assume os sentidos de dicotômico e optativo. Bela diz que, em seu ponto de vista, "gênero" "[...] é o que diferencia e identifica os homens e as mulheres; essa é a definição tradicional”. Enquanto Moana, apresenta "gênero" como “[...]aquilo com o qual se pode identificar, sendo da mesma origem, porém, diferenciando-se homens de mulheres (masculino do feminino).

A definição binária de gênero está presente nas falas das professoras por mencionarem os polos masculino e feminino como referência, apenas; embora Bela anuncie que essa é uma definição tradicional. Quando indagadas sobre como o gênero deveria ser trabalhado na escola, a professora Moana trouxe em sua fala que:

[...] o tema gênero acaba por dividir opiniões, tanto de pais quanto de educadores. Não acredito que deva ser totalmente banido dos currículos, porém deve ser tratado com sutileza, justamente por gerar tanta polêmica. Já que a comunidade e os pais podem e devem participar da elaboração/reelaboração do PPP, essa discussão, antes do início do ano letivo, possibilitaria uma conclusão comum a todos, evitando discursos distorcidos e uma homogeneidade quanto à temática.

Moana percebe a tensão que envolve a temática de "gênero"; mas, leva a entender que sua presença no currículo deve ser parcial, devido às polêmicas contemporâneas. Para tanto, ensaia uma alternativa de trabalho com gênero, nas escolas, ao situar o trabalho coletivo e a (re)elaboração do PPP, como forma de construir, democraticamente, o currículo, evitando distorções em relação à temática de gênero.

Bela, por sua vez, diz: "[...] acredito que esse tema deve ser encarado com naturalidade, que só deve ser dada ênfase, caso haja necessidade". As questões de gênero, presentes na escola, são tratadas como "tema", gerador de polêmicas e, por isso mesmo, abordado de forma sutil e pontual na prática pedagógica. 
As falas revelam que, embora as professoras definam a importância de trabalhar a temática sobre gênero na escola, há ressalvas quanto à aceitação e necessidade dessa discussão. O início da fala da professora Moana sugere sua eliminação parcial do currículo, quando diz que o tema não deve ser banido totalmente. Numa perspectiva binária, de masculino e feminino, as professoras sinalizam que o trabalho com gênero pode ocorrer, se for necessário, de comum acordo, apenas em algum momento específico ou situação; e ainda, de forma sutil. Entretanto, o ensaiar uma alternativa de trabalho com gênero, de forma coletiva e democrática, a professora Moana indica a pertinência da temática.

Pelo tema ser "polêmico", as professoras mostram que é preferível evitar discussões a esse respeito, ou em situações específicas. Elas não conseguem perceber que "gênero", para além de uma temática, diz da vida de todas e todos, envolve relações de poder.

O trabalho com gênero, para as professoras, assume uma função optativa no currículo; pois, quando provocadas sobre as intervenções em seus trabalhos, em sala de aula, elas se posicionam: Bela, de forma direta, diz: “não!”. E Moana diz: "Em minhas aulas, busco, de maneira suave, abordar a temática, uma vez que, independente da faixa etária, as curiosidades vão surgindo e a grande maioria não tem a oportunidade de esclarecer suas dúvidas em casa". E quanto ao trabalho com gênero, Moana afirma: “[...] na escola, de uma maneira geral, não sei ao certo; uma vez que não está presente, explicitamente, nos currículos, o que torna, o trabalho com gênero, optativo para o educador".

Assim, percebemos que a discussão sobre gênero nem sempre é tratada pelas professoras, que parecem ter receio de investir na discussão. Quando muito, suas falas revelam que a "temática" é abordada de forma optativa na escola, cabendo ao/à educador/a fazer suas escolhas. Além disso, a fala de Moana situa a discussão de gênero como "temática" secundária; pois, para ela, não tem presença efetiva no currículo. Desse modo, podemos inferir que há conteúdos específicos, por isso explícitos, que têm espaço privilegiado, e, por serem considerados "mais importantes”, são garantidos na prática docente.

As concepções binárias de gênero, apresentadas pelas professoras e a importância do trabalho com gênero, no currículo, pode revelar implicações na prática, com os contos de fadas. Se para as professoras "gênero" não é uma categoria necessária no trabalho com 
crianças, dificilmente atentarão para as intervenções, no que se refere aos estereótipos de gênero, presentes nos contos de fadas.

Dentre as categorias que emergiram das falas, a identificação das crianças com as e os personagens foi evidenciada na relação entre gênero e contos de fadas. Abordando as professoras sobre o interesse dos/das estudantes em relação aos contos de fadas, percebemos na fala de Moana que "[...] o contexto de maneira geral, desperta o interesse; em alguns casos há a identificação com os personagens [...]". A identificação das crianças com as/os personagens pode influenciar nas construções de gênero, sobretudo, se as representações, os papeis, as relações dessas/desses personagens não forem problematizados/as.

Para Aguiar e Barros “[...] fadas, bruxas, princesas e príncipes são personagens que incorporam problemas típicos do cotidiano, permitindo que a criança estabeleça uma simbologia de identificação com a história e, em muitas situações, coloque-se no lugar do personagem" (2015, p.3). O risco dessa identificação com a/o personagem incorre nos padrões binários de gênero, que, na realidade, têm implicações de relações de poder, desigualdade e violência.

A professora Moana apresenta em sua fala que: “O período da segunda infância é bastante ativo para as crianças; elas estão constantemente explorando o mundo a sua volta. Nessa fase, é comum a identificação com outras pessoas. No caso dos contos (principalmente quando assistem), acabam por absorver modos, falas e costumes". Através dos contos de fadas as crianças apreendem modelos, passados, sobretudo, pelas imagens que não são problematizadas pela prática pedagógica docente.

Bela acrescenta que as imagens das princesas chamam a atenção das meninas, quando diz: “[...] as princesas são admiradas por sua beleza, e muitas querem ser parecidas com elas [...]". Percebemos, na fala de Bela, que os contos de fadas reproduzem modelos e padrões estéticos para as meninas. Ainda em sua fala, Bela acrescenta que as meninas "[...] compram materiais escolares das suas princesas favoritas [...]". Nesse sentido, percebemos as relações de gênero e a influência dos artefatos culturais, no nosso caso, nos contos de fada. Para além do "consumo" das imagens, das representações de personagens, as crianças consomem, 
literalmente, produtos que veiculam esses padrões. Geralmente esses produtos reproduzem os modelos binários de gênero, revelando que são potentes artefatos culturais.

O desejo de identificação das crianças com a/o personagem, acontece a partir da influência das imagens, produzidas por uma indústria cultural; e veiculada, também, pelos contos de fadas. Desse modo, as crianças podem ter suas aspirações, crenças, desejos, suas estéticas, influenciadas por esses padrões de gênero. $O$ trabalho educativo, com gênero e sexualidade, bem como, com classe e raça, pode contribuir com a revisão desses padrões, através da releitura das imagens, textos e relações.

Giroux (2015), ao tratar dos filmes da Disney, como "máquinas de ensino" de uma "política de representação", chama os/as trabalhadores/as culturais para compreender o significado social, político e identitário das mensagens emitidas pelo sentido da "fantasia", sobretudo, atravessado por construções de gênero.

Ainda com relação ao desejo de identificação, Moana assegura que: "Preconceber a imagem de uma pessoa/personagem, coisa ou situação, é bastante comum nesse período da infância; principalmente porque, inconscientemente, a família acaba influenciando, ao chamar as meninas de "princesas ou princesinhas"; e os meninos, de "príncipes". Bela também percebe essa atuação, quando diz: "[...] como trabalho muito esse contexto de "príncipe e princesa", os percebo com essa vontade de querer ser o príncipe ou a princesa".

A identificação e/ou reflexão das crianças acerca dos atravessamentos de gênero nas histórias e personagens dependerão, sobretudo, da intencionalidade pedagógica do/a professor/professora e do trabalho desenvolvido. A discussão relativa à desnaturalização dos papeis de gênero, dificilmente, é realizada pela família.

Embora as professoras afirmem realizar a inferência e a releitura desses contos, não dão ênfase às questões de gênero. Bela diz: “[...] ao fim da história, realizo perguntas e trago situações contadas na narrativa, para a vida real". A professora revela maior cuidado na prática pedagógica docente com a literatura, através do trabalho interventivo; porém, o trabalho com gênero, nos contos de fadas, não aparece diretamente, não é mencionado.

Os contos de fadas são trabalhados no cotidiano de sala de aula pelas professoras, que identificam os atravessamentos de gênero nas histórias; mas, não fazem intervenções 
específicas, por conceberem "gênero" enquanto temática optativa; além disso, por compreenderem que essa é uma discussão polêmica e pontual, que exige aceitação prévia e consensual.

\section{OS CONTOS DE FADAS E AS (RE)CONSTRUÇÕES DE GÊNEROS}

Os contos de fadas, enquanto narrativas sobre a vida, gênero literário, conteúdo e recurso pedagógico, podem contribuir com o desenvolvimento da imaginação, criatividade, aprendizagem, enfrentamentos e construção identitária, sobretudo, de crianças. Nos contos também estão presentes os atravessamentos de gênero, sexualidade, raça e classe. Através das/dos personagens, das relações, dos textos, cores, etc., as histórias veiculam construções de gêneros. Desse modo, os contos são situados, neste trabalho, como potentes artefatos de gênero, que podem influenciar na definição de papeis binários (meninos e meninas), sobretudo, através dos discursos veiculados pelos clássicos modelos de princesas e de príncipes.

Os novos contos, presentes nas salas de aula, despontam com construções de gênero, que se contrapõem aos modelos idealizados de princesas, príncipes e relações padronizadas. Enquanto referentes pedagógicos, os novos contos podem sinalizar para a problematização dos papeis de gênero, inclusive, porque as crianças também se identificam com a ressignificação das/dos personagens e enredos (VIDAL, 2008); embora as professoras digam da preferência das crianças pelo que nomeiam de "contos clássicos".

Este artigo trata da relação entre os contos de fadas e gênero, a partir da perspectiva das professoras e do diálogo com teóricas/os, que evidenciam as categorias de análise: contos de fadas, gênero e a relação entre contos de fadas e gênero.

Os contos são utilizados pelas professoras por estarem associados à fantasia e enquanto recurso pedagógico capaz de estimular a criatividade e imaginação das crianças; porém, sem trato específico em relação a gênero. Embora digam perceber os atravessamentos de gênero nas histórias, principalmente, em relação às representações femininas e aos 


\section{Revista
Debates Insubmissos}

modelos estereotipados de príncipes e de princesas; revelam não tratar de forma específica a discussão.

A presença dos "novos contos", que "borram" os territórios binários de gênero, também não é explorada pelas professoras. Elas dizem perceber mudanças nos enredos e personagens, que trazem representações de princesas mais empoderadas. Para as professoras, o trabalho com gênero na escola é gerador de conflitos e relaciona-se a situações específicas, que demandam aceitação, sobretudo, das famílias.

Podemos inferir que há um certo silenciamento na prática pedagógica, no que se refere a intervenções específicas relacionadas a gênero e sexualidade. Essa postura tem a ver com uma concepção ligada a padrões binários de gênero, que contribui para a naturalização dos estereótipos presentes nos contos clássicos. Como também, ao atribuírem a "gênero" uma dimensão optativa no currículo, considerarem "gênero" um tema polêmico, gerador de conflitos, que demanda aceitação, as professoras indicam não realizar intervenções específicas nessa direção.

Algumas situações revelam transformações em curso na prática pedagógica docente: a escolha das obras por parte das crianças, a presença dos novos contos na sala de aula, a percepção das professoras em relação aos estereótipos e a sugestão para o trabalho coletivo com gênero no currículo, a partir do PPP. Desse modo, a relação entre os contos de fadas e gênero na prática pedagógica mostra que avanços, embora tímidos, despontam no cotidiano da sala de aula, podendo instigar as professoras a desenvolverem trabalhos mais direcionados a gênero e contos de fadas.

Sinalizamos, portanto, para a importância de investigação em contos de fadas, enquanto artefato de gênero, presente nas práticas pedagógicas docente e discente.

\section{REFERÊNCIAS}

ABRAMOVICH, Fanny. Literatura infantil: gostosuras e bobices. 4. ed. São Paulo: Scipione, 1994 
AGUIAR, Eveline Lima de Castro e BARROS, Marina Kataoka. A representação feminina nos contos de fadas das animações de Walt Disney: a ressignificação do papel social da mulher. XVII Congresso de Ciências da Comunicação na Região Nordeste - Natal - RN Natal - RN. 2015. Disponível em: http://www.portalintercom.org.br/anais/nordeste2015/ resumos/R47-1959-1.pdf Acesso em: 20 de maio de 2018.

BARDIN, Laurence. Análise de Conteúdo. Trad. Luís Antero Reto e Augusto Pinheiro. Lisboa, Portugal: Edições 70, 1977.

BASTOS, Rodolpho Alexandre Santos Melo; NOGUEIRA, Joanna Ribeiro. Estereótipos de gênero em contos de fada: uma abordagem histórico-pedagógica. Revista Dimensões, v. 36, jan.-jun. 2016, p. 12-30. Disponível em: http://www.periodicos.ufes.br/dimensoes/article/ viewFile/13864/9817 Acesso em: 25 de abril de 2018.

BENTO, Berenice. A reinvenção do corpo: sexualidade e gênero na experiência transexual. Rio de Janeiro: Garamond, 2006.

BETTELHEIM, B. A Psicanálise dos contos de fadas. Rio de Janeiro: Paz e Terra, 2002.

BUSS-SIMÃO, Márcia. Meninos entre meninos num contexto de educação infantil: um olhar sobre as relações sociais de gênero na perspectiva de crianças pequenas. $3^{\mathbf{a}}$ Reunião Anual da Anped. 2012. Disponível em: http://www.anped.org.br/sites/default/files/ gt07-1364_res.pdf Acesso em: 25 de abril de 2018.

BUTLER, Judit. Problemas de gênero: feminismo e subversão da identidade. Tradução Renato Aguiar. 5. ed. Rio de Janeiro: Civilização Brasileira, 2013.

CANEN, Ana; MOREIRA, Antônio Flávio Barbosa (Orgs.). Ênfases e omissões no currículo. Campinas, SP: Papirus, 2001. (Coleção Magistério: Formação e Trabalho Pedagógico).

COELHO, Nelly Novaes. O conto de fadas. São Paulo: Ática, Literatura infantil: teoriaanálise - didática. São Paulo: Ática, 1993.

.O Conto de Fadas: símbolos, mitos e arquétipos. São Paulo: Difusão Cultural do Livro, 2003.

CORSO, D. L. e CORSO, M. Fadas no divã: psicanálise nas histórias infantis. Porto Alegre: Artmed, 2006. 
DAROS. Thuinie Medeiros Vilela. Problematizando os gêneros e as sexualidades através da literatura infantil. Revista Práticas de Linguagem. Juiz de Fora, V. 3, n. 2, p. 172-186, juldez. 2013. Disponível em: http://www.ufjf.br/praticasdelinguagem/files/2014/01/172---186Problematizando-os-gêneros-e-a-sexualidade-através-da-literatura-infantil.pdf Acesso em: 20 de maio de 2018.

FALCONI, I. M. e FARAGO, A. C. Contos de Fadas: origem e contribuições para o desenvolvimento da criança. Cadernos de Educação: Ensino e Sociedade, Bebedouro-SP, n. 2, p. 85-111, 2015. Disponível em: http://unifafibe.com.br/revistasonline/arquivos/ cadernodeeducacao/sumario/35/06042015200330.pdf Acesso em: 20 de maio de 2018.

GIROUX, H. MCLAREN, P. Por uma pedagogia crítica da representação. In: SILVA, T. T. MOREIRA, A F. (org.). Territórios contestados: o currículo e os novos mapas políticos e culturais. Petrópolis: Vozes, 1995. p.144-158.

A Disneyzação da Cultura Infantil. In: SILVA, T. T. MOREIRA, A F. (org.). Territórios contestados: o currículo e os novos mapas políticos e culturais. Petrópolis: Vozes, 1995.p. 49-79.

GOMES, Romeu. A análise e interpretação de dados de pesquisa qualitativa. In: Minayo, M.C.S. Pesquisa Social: teoria, método e criatividade. 29. ed. Petrópolis, RJ: Vozes, 2002.

LOURO, Guacira Lopes. Gênero, sexualidade e educação: Uma perspectiva pósestruturalista. Petrópolis, RJ: Vozes, 1997.

MINAYO, Maria Cecília de Souza (org.). Pesquisa social: teoria, método e criatividade. 29. ed. Petrópolis, RJ: Vozes, 2002.

MANZINI, José Eduardo. Entrevista semiestruturada: análise de objetivos e de roteiros. Programa de Pós Graduação em Educação, Unesp, Marília . Apoio: CNPq, 2004.

OLIVEIRA, P. S. T. de. A construção dos contos de fadas no processo de aprendizagem das crianças. 62 p. 2010. Trabalho de Conclusão de Curso - UNEB, Salvador, 2010.

SABAT, Ruth. Pedagogia Cultural, gênero e sexualidade. Revista Estudos Feministas. Florianópolis, Vol. 9, p. 9-21, $2^{\circ}$ semestre, 2001. Disponível em: https://periodicos.ufsc.br/ index.php/ref/article/view/S0104-026X2001000100002/8891 Acesso em: 20 de maio de 2018.

SALGADO, Raquel Gonçalves; FERRARINI, Anabela Rute Kohlmann; LUIZ, George Moraes de. Crianças mirando-se no espelho da cultura: corpo e beleza na infância contemporânea. 35 $^{\mathbf{a}}$ Reunião Anual da Anped. 2012. Disponível em: http://www.anped.org.br/sites/default/files/gt07-2261_int.pdf Acesso em: 25 de abril de 2018. 
SCOTT, J. Gênero: uma categoria útil de análise histórica. Educação e Realidade. Porto Alegre, v. 16, n. 2, p. 5-22, jul/dez, 1990.

SEVILLA, Gabriela Garcia. Pedagogias de gênero e sexualidade em artefatos culturais: reflexões sobre uma experimentação. $37^{\text {a }}$ Reunião Nacional da Anped. 2015. Disponível em: http://www.anped.org.br/sites/default/files/trabalho-gt23-4463.pdf Acesso em: 25 de abril de 2018.

SIQUEIRA, Tatiana Lima. Joan Scott e o papel da história na construção das relações de gênero. Revista Ártemis, João Pessoa, Vol. 8, p. 110-118, junho 2008. Disponível em: http://www.periodicos.ufpb.br/index.php/artemis/article/view/2310/2032 Acesso em: 20 de maio de 2018.

VIDAL, Fernanda Fornari. Os "novos contos de fadas": ensinando sobre relações de gênero e sexualidade. Fazendo gênero 8 - corpo, violência e poder. Florianópolis, 2008. Disponível em: http://www.fazendogenero.ufsc.br/8/sts/ST44/Fernanda_Fornari_Vidal_44.pdf Acesso em: 10 de outubro de 2017.

Submetido em: 27/08/2018

Aprovado em: 08/12/2018 